\title{
\begin{tabular}{l|l|l} 
Jurnal Eksplorasi Akuntansi & e-ISSN : 2656-3649 (Online) \\
Vol. 3, No 2, Mei 2021, Hal 316-328 & http://jea.ppj.unp.ac.id/index.php/jea/index
\end{tabular}
}

\section{Pengaruh CAR, NPL, LDR dan BOPO terhadap Return On Assets (ROA) pada Bank Terdaftar di Bursa Efek Indonesia Tahun 2017-2019}

\author{
Panji Maulana $^{1 *}$, Sany Dwita ${ }^{2}$, Nayang Helmayunita ${ }^{3}$ \\ 1,2,3 Jurusan Akuntansi, Fakultas Ekonomi, Universitas Negeri Padang \\ *Korespondensi: panji_maulana@gmail.com
}

\begin{abstract}
This research aims to determine the effect of Capital Adequacy Ratio (CAR), Loan to Deposit Ratio (LDR), Non Performing Loan (NPL), dan Operational Efficiency Ratio (OER) of commercial banks listed on the Indonesia Stock Exchange 2017-2019. Population in this research while sample was defined bu purposive sampling method and 28 Banks as sample. Type of data that we used was secondary data (panel data) from www.idx.com and company's website. Data collection method used documentation method and multiple regression analysist method. The result are Capital Adequacy Ratio (CAR), Loan to Deposit Ratio (LDR) have no effect on ROA.
\end{abstract}

Keywords: Return on Asset; Capital Adequacy Ratio; Loan to Deposit Ratio; Non Performing Loan; Operational Efficiency Ratio.

\section{How to cite}

Maulana, Panji., Dwita, Sany., Helmayunita, Nayang. (2021). Pengaruh CAR, NPL, LDR dan BOPO terhadap Return On Assets (ROA) pada Bank Terdaftar di Bursa Efek Indonesia Tahun 2017-2019. Jurnal Eksplorasi Akuntansi, 3(2), 316-328.

\section{PENDAHULUAN}

Perbankan di dalam negeri terancam keberadaanya akibat pandemi Covid-19, bahkan ancaman krisis ekonomi global sudah hampir di depan mata. Hal ini menyebabkan pelaku industri perbankan dihadapi pada situasi tidak kondusif akibat persaingan antar bank semakin tinggi dengan berbagai produk dan bersifat kompetitif. Permasalahan yang rumit ini telah menciptakan persaingan baru dalam dunia perbankan. Kasmir (2012) menyatakan bahwa neraca keuangan pada instansi merupakan bentuk laporan keuangan agar informasi dapat dilihat oleh pihak luar bank, seperti bank central, publik, dan pemilik modal. Fungsi dari laporan keuangan adalah untuk melihat resiko yang akan di terima ketika menanamkan modal di instansi tersebut.

Investigasi laporan keuangan digunakan untuk penghitungan rasio keuangan berfungsi untuk menilai kondisi moneter pada berbagai waktu, dengan target fundamental memberikan evaluasi dan prakiraan potensial tentang pelaksanaan di masa depan. Eksekusi bank dilihat dalam menciptakan manfaat atau produktivitas yang dapat diperkirakan dengan Return on Equity (ROE) dan Return on Asset (ROA). ROA berpusat disekitar kapasitas organisasi untuk 
memperoleh pendapatan dalam aktivitas organisasi, sementara ROE hanya memperkirakan pengembalian yang didapat dari kepentingan pemilik organisasi.

ROA dipilih sebagai rasio kinerja bank, dengan alasan: Pertama, ROA dapat dilihat seberapa baik kapasitas bank menangani sumber dayanya secara umum. Proporsi ini sekaligus menjadi penanda efektifitas administrasi bank yang menunjukkan kemampuan pemerintah dalam mengelola sumber dayanya demi keuntungan (Mudrajad Kuncoro, 2002:234). Tan \& Anchor (2016) mengungkapkan bahwa secara tradisional, literatur perbankan menggunakan Z-score untuk mengukur risiko insolvensi yaitu sebagai berikut: (1) menghitung pengembalian aset ditambah kapitalisasi; (2) menghitung standar deviasi pengembalian atas aset; dan (3) membagi pengembalian atas aset ditambah kapitalisasi dengan standar deviasi pengembalian atas aset. Kedua, ROA untuk melihat eksekusi antar bank mulai dari satu periode ke periode berikutnya. Menurut Valentina Flamini et al (2009), selain bermanfaat untuk mengetahui tingkat efektivitas sumber daya eksekutif dalam menghasilkan keuntungan, ROA juga merupakan rasio yang terkenal untuk membedakan pelaksanaan antar bank dari satu periode dengan periode berikut.

Pada penelitian ini penulis, melihat pengaruh Capital Adequacy Ratio (CAR), Loan to Deposit Ratio (LDR), Non Performing Loan (NPL), dan Operational Efficiency Ratio (OER) atau BOPO terhadap ROA. Karena lemahnya CAR, LDR, NPL, dan BOPO mengakibatkan berkurangnya akses ke produk dan layanan jasa keuangan, biaya yang lebih tinggi terkait dengan layanan, dan peningkatan kemungkinan memasuki kebangkrutan (Birkenmaier, 2012). Berdasarkan hasil eksplorasi yang dikemukakan oleh Wahyuni (2016) menunjukkan bahwa LDR tidak berpengaruh terhadap ROA, CAR tidak berpengaruh terhadap ROA, tapi terdapat pengaruh positif dan signifikan BOPO terhadap ROA. Penelitian yang dilakukan oleh Setyowati \& Budiwinarto (2017) menunjukkan bahwa NIM berpengaruh positif terhadap ROA, BOPO berpengaruh negatif terhadap ROA, LDR tidak berpengaruh terhadap ROA, NPL berpengaruh negatif terhadap ROA, dan CAR tidak berdampak pada ROA. Selain itu, dari hasil pengujian yang dilakukan oleh Avrita \& Pangestuti (2016) menunjukkan bahwa CAR memiliki pengaruh negatif yang signifikan terhadap ROA, NPL mempunyai pengaruh yang sugnifikan terhadap ROA, LDR tidak berpengaruh dan negatif terhadap ROA, NIM memiliki pengaruh yang signifikan pada ROA, BOPO berpengaruh signifikan secara negatif terhadap ROA. Menurut Warsa \& Mustanda (2016), CAR berpengaruh positif terhadap ROA, LDR berpengaruh positif terhadap ROA, NPL berpengaruh negatif terhadap ROA. Selain itu, penelitian yang dilakukan oleh Marliana \& Anan (2015) menunjukkan bahwa CAR, LDR dan NIM berpengaruh positif dan signifikan terhadap ROA, BOPO berpengaruh negatif terhadap ROA.

Rumusan masalah pada penelitian ini adalah (1) apakah CAR mempengaruhi ROA bank umum yang tercatat di Bursa Efek Indonesia tahun 2017-2019 ?, (2) apakah LDR berpengaruh terhadap ROA bank umum yang tercatat di Bursa Efek Indonesia tahun 20172019 ?, (3) apakah NPL mempengaruhi ROA bank umum yang tercatat di Bursa Efek Indonesia tahun 2017-2019 ?, (4) apakah BOPO mempengaruhi ROA bank umum yang tercatat di Bursa Efek Jakarta tahun 2017-2019?

\section{LANDASAN TEORI DAN PENGEMBANGAN HIPOTESIS Profitabilitas}

Osborne, Fuertes, \& Milne (2017) menyarankan bahwa bank dengan profitabilitas tinggi memiliki lebih banyak insentif dalam membatasi pengambilan risiko dengan memegang tingkat modal yang lebih tinggi. Profitabilitas diprediksi memiliki dampak signifikan dan negatif terhadap risiko modal. Tingkat modal tinggi di bank dengan tingkat profitabilitas yang lebih tinggi memungkinkan mereka untuk terlibat sepenuhnya dalam berbagai transaksi pinjaman jangka pendek dan jangka panjang, dan ini mengarah pada pengurangan tingkat 
likuiditas bank, yang mengarah ke tingkat risiko likuiditas yang lebih tinggi. Idealnya ROA suatu bank adalah $1.5 \%$. Jika bank mendapatkan keuntungan di bawah nilai yang ditetapkan oleh Bank Indonesia, berarti bank belum bisa mengelolah aset-asetnya secara optimal.

\section{Indikator Rasio Keuangan}

\section{a. CAR (Capital Adequacy Ratio)}

Menurut Buffer Theory of Capital Adequacy, bank dapat memilih untuk menahan dari kelebihan modal untuk mengurangi kemungkinan jatuh di bawah persyaratan modal yang sah, terutama jika rasio kecukupan modal mereka sangat volatile (Chandrasegaran, 2020). Dalam hal nilai aset bank lebih rendah dari total kewajibannya, bank menjadi bangkrut dan pemegang ekuitas cenderung memilih untuk default pada kewajiban bank (Joyce Jepkosgei Kipruto, Matanda, \& Osodo, 2017). Capital Adequacy Ratio (CAR) dapat diukur sebagai berikut:

$$
C A R=\frac{\text { Bank Capital }}{\text { Risk Weighted Assets }}
$$

\section{b. LDR (Loan to Deposit Ratio)}

LDR dapat digunakan oleh otoritas untuk mengatasi risiko likuiditas struktural (jangka panjang) dan siklus (jangka pendek). Dimensi struktural mengacu pada ketidakcocokan antara pinjaman dan simpanan nasabah yang mengikuti model bisnis bank (Van den End, 2016). Berg (2012) menjelaskan hubungan antara pinjaman dan simpanan dalam konteks model aliran keuangan. Dalam pendekatan itu, simpanan dapat menciptakan pinjaman, karena peningkatan dana simpanan meningkatkan posisi likuiditas bank dan dengan demikian ruang mereka untuk memberikan pinjaman (pinjaman adalah mitra moneter dari simpanan). Sebaliknya, pinjaman bank cenderung menciptakan simpanan, karena dana yang diterima oleh peminjam akan berakhir dalam simpanan, baik di rekening peminjam atau di rekening rekanannya yang menerima pembayaran.

Batas ideal LDR adalah apabila batas bawah Loan to Deposit Ratio (LDR) adalah 78\% dan batas atas Loan to Deposit Ratio (LDR) adalah 92\%. Apabila batas atas LDR sampai 100\% dianggap terlalu agresif. Perhitungan LDR sebagai berikut:

$$
\mathrm{LDR}=\frac{\text { Total Credit Given }}{\text { Total Deposit from Third Party }}
$$

\section{c. NPL (Non Performing Loan)}

Perusahaan keuangan telah lama menggunakan rasio kredit macet (NPL) sebagai indikator kinerja. Tingkat pinjaman yang belum dibayar sebagai proporsi dari keseluruhan pinjaman, dianggap sebagai 'non-performing' setelah mereka mencapai tiga bulan sejak jatuh tempo (Epure \& Lafuente, 2015) dipandang sebagai indikator kinerja pinjaman dari pinjaman lembaga keuangan portofolio. Nilai NPL tidak boleh lebih dari 5\%, hal ini penting untuk menentukan besarnya cadangan minimum penghapusan aktiva produktif diberikan bank untuk menutupi potensi kerugian. Berikut ini adalah perhitungan nilai NPL:

$$
\mathrm{NPL}=\frac{\text { Bad Debt }}{\text { Total Credit }}
$$

\section{d. BOPO (Biaya Operasional Pendapatan Operasional)}

Matindas, Pangemanan, \& Saerang, (2015) mengemukakan bahwa semakin rendah nilai BOPO, semakin efisien bank menggunakan biaya operasional dalam menjalankan bisnisnya. Sehingga benefit yang diperoleh bank akan semakin besar, dan sebaliknya jika nilai BOPO semakin tinggi, semakin tidak efisien bank menggunakan biaya operasional dalam bisnisnya. 
Peraturan Bank Indonesia 2013 menetapkan bahwa batas maksimum rasio Biaya Operasional dan Pendapatan Operasional (BOPO) adalah 85\%. Berikut ini adalah perhitungan nilai BOPO:

$$
\mathrm{BOPO}=\frac{\text { Operational Costs }}{\text { Operating Income }}
$$

\section{Hubungan CAR dengan ROA}

CAR merupan nilai kecukupan modal digunakan untuk mengevaluasi kesehatan suatu bank. Kecukupan modal diidentikkan dengan penataan modal sendiri yang diharapkan dapat menutupi kerugian yang timbul dari pengembangan sumber daya bank, yang pada dasarnya sebagian besar merupakan aset pihak. Jika CAR meningkat, maka kemampuan bank dalam menanggung risiko pembiayaan juga akan meningkat. Penelitian yang dilakukan oleh Wibowo, Syaichu, \& Manajemen (2013); Erlangga \& Mawardi (2016); Munir (2018); Oktaviani, Suyono, \& Mujiono (2019) \& Madugu, Ibrahim, \& Amoah (2020) mengungkapkan bahwa bahwa CAR tidak berpengaruh signifikan terhadap ROA.

H1: CAR berpengaruh positif dan signifikan terhadap ROA bank umum yang terdaftar di Bursa Efek Indonesia tahun 2017-2019.

\section{Hubungan LDR dengan ROA}

LDR tinggi menunjukkan bahwa fondasi moneter tidak likuid atau bank tidak dapat memenuhi kewajibannya, sedangkan tingkat proporsi yang lebih rendah menunjukkan bahwa bank bersifat likuid atau bank dapat memenuhi kewajibannya. Bank yang berada dalam kondisi tidak likuid akan mengalami kendala dalam merebut kembali kepercayaan masyarakat dan melakukan kegiatan operasional bank yang fundamental dalam melakukan pengalihan yang berakibat pada profitabilitas yang tinggi dan rendah.Pernyataan tersebut sejalan dengan study yang dilakukan oleh Avrita \& Pangestuti (2016); Oktaviani et al. (2019);Dewi, Mulyadi, \& Adurrakhman (2015); Majidi (2016) \& Atmoko, Amboningtyas, \& Fathoni (2018) yang menyatakan bahwa Loan to Deposit Ratio tidak berpengaruh negatif signifikan terhadap profitabilitas (ROA).

H2: LDR mempengaruhi ROA bank umum yang terdaftar di Bursa Efek Indonesia tahun 2017-2019 secara positif dan signifikan.

\section{Hubungan NPL dengan ROA}

Pinjaman macet mengikis profitabilitas bank sehingga bank bisa mengeluarkan biaya pembuangan yang besar. Pinjaman Bermasalah Aset memiliki biaya peluang, di mana aset produktif tanpa bunga (terutama dalam bentuk uang) dapat diinvestasikan di tempat lain dan memberikan penghasilan. Selain itu, Bank juga diharuskan untuk membuat cadangan kerugian atas aset bermasalah yang pada gilirannya mempengaruhi profitabilitas dan ada biaya yang terkait dengan upaya untuk memulihkan kredit macet.

Kinerja keuangan adalah diukur dalam hal pengembalian aset (ROA) sementara kredit bermasalah (NPL) diukur sebagai rasio NPL (yang dihitung sebagai persentase kredit bermasalah terhadap pinjaman bruto, dengan demikian NPL Bruto / Pinjaman bruto). Hasil study yang dilakukan oleh Mardi \& Faradila (2016); Yusriani (2018); Vernanda \& Widyarti (2016); Amin Moh (2019) \& Alshebmi, Mohammad Adam, Mustafa, Thomran, \& Fathelbab (2020) yang menyatakan bahwa Hasil korelasi menunjukkan hubungan lemah, negatif secara signifikan antara rasio kredit bermasalah (NPL) dan rasio pengembalian aset (ROA).

H3: NPL berpengaruh positif dan signifikan terhadap ROA bank umum yang terdaftar di bursa efek Indonesia tahun 2017-2019 


\section{Hubungan BOPO dengan ROA}

Biaya Operasional terhadap Pendapatan Operasional (BOPO) atau Operating Efficiency Ratio (OER) adalah membandingkan biaya operasional dengan pendapatan operasional. Rasio ini berfungsi mengukur tingkat efisiensi dan kemampuan bank dalam melakukan kegiatan operasional. Semakin kecil nilai rasio ini, semakin efisien bank mengeluarkan biaya operasional, dengan efisiensi biaya membuat laba diambil oleh bank, dengan cara profitabilitas. Pernyataan didukung oleh hasil riset yang dilakukan oleh Ahmed Mennawi \& Ahmed(2020); Wibowo et al. (2013); Amin Moh (2019); Putra (2020) \& Hosen, Jie, Muhari, \& Khairman (2019) yang menyatakan bahwa BOPO memiliki dampak negatif dan signifikan terhadap profitabilitas bank.

H4: BOPO berpengaruh negatif dan signifikan terhadap ROA bank umum yang terdaftar di bursa efek Jakarta Tahun 2017-2019

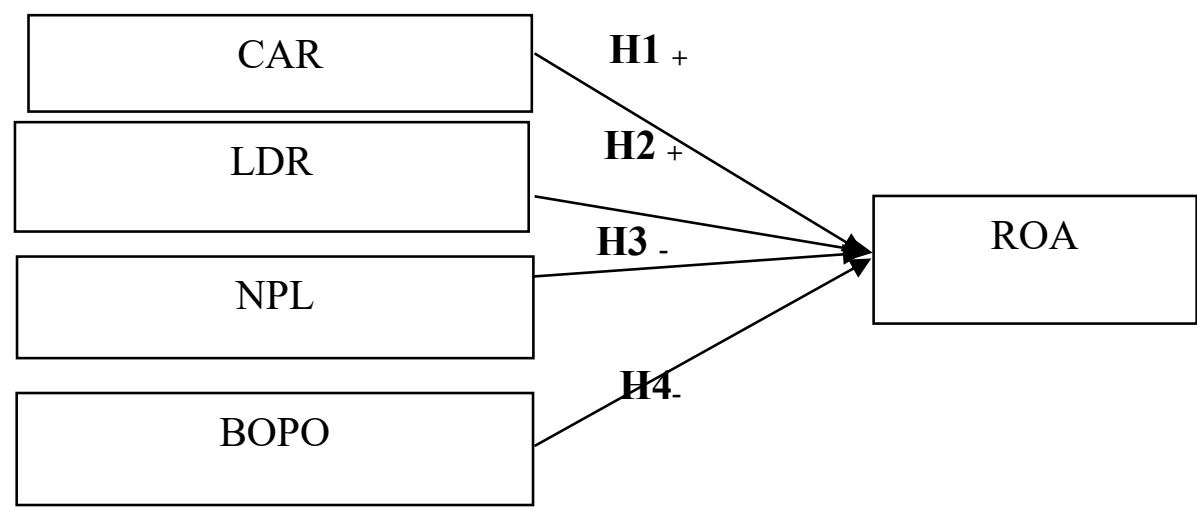

\section{Gambar 1. Kerangka Konseptual}

\section{METODE PENELITIAN}

Penelitian ini adalah eksplorasi kuantitatif, penelitian ini mengukur tingkat hubungan antara berbagai faktor yang dipertimbangkan agar peneliti memiliki opsi untuk membedakan pentingnya setiap variabel. Populasi yang digunakan adalah 43 bank yang tercatat di Bursa Efek Indonesia. Prosedur pemeriksaan yang digunakan dalam penelitian ini menggunakan purposive sampling yaitu metode pengujian yang didasarkan pada pemikiran langkahlangkah tertentu (Sekaran \& Bougie (2016). Kriteria bank yang diteliti adalah: (1) Bank umum yang tercatat pada BEI selama rentang waktu 2017-2019. (2) Bank umum yang secara rutin mendistribusikan total laporan keuangan selama rentang waktu 2017-2019, (3) Perusahaan yang tidak mengalami kerugian selama periode 2017-2019. Data yang digunakan dalam penelitian ini yaitu data panel, dimana data panel tersebut merupakan gabungan dari data time series dan data cross section. Metode pengumpulan data dalam penelitian ini dilakukan dengan cara dokumentasi dari www.idx.co.id.

Untuk membuktikan kebenaran hipotesis maka digunakan metode analisis kuantitatif. Analisis kuantitatif bertujuan untuk menguji hipotesis yang telah ada. Dalam penelitian ini analisis kuantitatif dilakukan dengan cara mengklasifikasikan data-data penelitian guna untuk mendapatkan informasi yang dibutuhkan dalam menganalisis. Pengujian dalam penelitian ini menggunakan SPSS 24.0. Adapun tahap-tahap pengujian yang dilakukan adalah sebagai berikut: (1) uji asumsi klasik yang terdiri dari uji normalitas, uji multikolinearitas, uji heteroskedastisitas, dan uji autokorelasi. (2) analisis koefisien determinasi $\left(\mathrm{R}^{2}\right)$, (3) Uji F, dan (4) Uji t. Adapun persamaan regresi (Ghozali, 2011): 


$$
y=\alpha_{0}+b_{1} C A R+b_{2} L D R+b_{3} N P L+b_{4} B O P O+b_{5} \beta+\varepsilon i
$$

Keterangan:

$$
\begin{aligned}
\mathrm{Y} & =\text { Profitabilitas }(\mathrm{ROA}) \\
\boldsymbol{b}_{\mathbf{1}} & =\text { Koefisien regresi dari CAR } \\
\boldsymbol{b}_{\mathbf{2}} & =\text { Koefisien regresi dari LDR } \\
\boldsymbol{b}_{3} & =\text { Koefisien regresi dari NPL } \\
\boldsymbol{b}_{\mathbf{4}} & =\text { Koefisien regresi dari BOPO } \\
\boldsymbol{\alpha}_{\mathbf{0}} & =\text { Konstanta } \\
\boldsymbol{\varepsilon} & =\text { Kesalahan residual (error) }
\end{aligned}
$$

\section{HASIL DAN PEMBAHASAN

\begin{tabular}{|c|c|c|c|c|c|c|}
\hline \multirow[b]{2}{*}{ Variabel } & \multirow{2}{*}{$\begin{array}{c}\mathrm{N} \\
\text { Statistic }\end{array}$} & \multirow{2}{*}{$\begin{array}{l}\text { Minimum } \\
\text { Statistic } \\
\end{array}$} & \multirow{2}{*}{$\begin{array}{l}\text { Maximum } \\
\text { Statistic } \\
\end{array}$} & \multicolumn{2}{|c|}{ Mean } & \multirow{2}{*}{$\begin{array}{c}\text { Std. Deviation } \\
\text { Statistic } \\
\end{array}$} \\
\hline & & & & Statistic & Std. Error & \\
\hline CAR & 84 & 2,20 & 66,43 & 21,78 & ,913 & 8,37 \\
\hline LDR & 84 & 50,61 & 163,10 & 88,89 & 1,91 & 17,53 \\
\hline NPL & 84 & 05 & 7,08 & 1,90 &, 17 & 1,53 \\
\hline BOPO & 84 & 58,20 & 99,04 & 82,40 & 1,15 & 10,50 \\
\hline ROA & 84 & ,09 & 4,00 & 1,73 &, 12 & 1,06 \\
\hline Valid N (listwise) & 84 & & & & & \\
\hline
\end{tabular} \\ Deskripsi Penelitian}

Uji terhadap 28 sampel yang tercatat di BEI telah sesuai standar. Waktu tahun yang digunakan dari 2017-2019. Pengukuran memberikan data tentang nilai terkecil, terbesar, ratarata, dan standar deviasi. Simpangan baku digunakan untuk melihat nilai variabel menyimpang dari nilai normalnya.

Tabel 1

Statistik Deskriptif

Berdasarkan tabel 1 menunjukan bahwa hasil analisis deskriptif statistik rasio kecukupan modal yang dilihat dari nilai $C A R$ menunjukan bahwa nilai terendah sebesar 2,20, nilai tertinggi sebesar 66,43 dan nilai rata-rata dari CAR sebesar 21,78, serta standar deviasi sebesar 8,37. Hasil analisis deskriptif statistik rasio LDR menunjukan bahwa nilai terendah sebesar 50.61, nilai tertinggi sebesar 163,10 dan nilai rata-rata dari LDR sebesar 88,89, serta standar deviasi sebesar 17,53. Hasil analisis deskriptif statistik rasio NPL menunjukan bahwa nilai terendah sebesar 0,05 , nilai tertinggi sebesar 7,08 dan nilai rata-rata dari NPL sebesar 0,17 , serta standar deviasi sebesar 1,53. Hasil analisis deskriptif statistik rasio BOPO menunjukan bahwa nilai terendah sebesar 58,20, nilai tertinggi sebesar 99,04 dan nilai ratarata dari BOPO sebesar 82,40, serta standar deviasi sebesar 10,50. Hasil analisis deskriptif statistik rasio ROA menunjukan bahwa nilai terendah sebesar 0,09 , nilai tertinggi sebesar 4,00 dan nilai rata-rata dari ROA sebesar 1,73, serta standar deviasi sebesar 1,06. 


\section{Uji Asumsi Klasik}

Uji Normalitas

Tabel 2

Uji Normalitas

One-Sample Kolmogorov-Smirnov Test

\begin{tabular}{|c|c|c|c|}
\hline \multicolumn{4}{|c|}{ One-Sample Kolmogorov-smirnov lest } \\
\hline & & & $\begin{array}{c}\text { Unstandardized } \\
\text { Residual }\end{array}$ \\
\hline \multicolumn{3}{|l|}{$\mathrm{N}$} & 84 \\
\hline \multirow[t]{2}{*}{ Normal Parameters ${ }^{\mathrm{a}, \mathrm{b}}$} & Mean & &, 000 \\
\hline & Std. Deviation & & ,291 \\
\hline \multirow[t]{3}{*}{ Most Extreme Differences } & Absolute & & ,091 \\
\hline & Positive & & ,091 \\
\hline & Negative & &,- 048 \\
\hline \multicolumn{3}{|l|}{ Test Statistic } & ,091 \\
\hline \multicolumn{3}{|l|}{ Asymp. Sig. (2-tailed) } &, $085^{\mathrm{c}}$ \\
\hline \multirow[t]{3}{*}{ Monte Carlo Sig. (2-tailed) } & Sig. & &, $472^{\mathrm{d}}$ \\
\hline & \multirow[t]{2}{*}{$99 \%$ Confidence Interval } & Lower Bound & ,459 \\
\hline & & Upper Bound & ,485 \\
\hline
\end{tabular}

a. Test distribution is Normal.

Berdasarkan Tabel 2, dapat dilihat bahwa estimasi Kalmograf-Smirnov (K-S) dari Asymp. Sig. (2-tailed) adalah 0,085. Karena Kalmograf-Smirnov (K-S)> 0,05, disimpulkan data terdistribusi normal.

\section{Uji Multikolinieritas}

Uji multikolinieritas ini adalah untuk membandingkan korelasi antar variabel dengan angka korelasi pembanding. Mengukur multikolinieritas dilihat dari nilai VIF dari masing-masing variabel. Jika nilai VIF lebih kecil dari 10, maka tidak terdapat multikolinieritas. Tabel 3 merupakan nilai VIF.

Tabel 3

Hasil Uji Multikolinieritas

\begin{tabular}{llcc}
\hline \multicolumn{3}{c}{ Coefficients $^{\mathbf{a}}$} \\
\hline \multirow{3}{*}{ Model } & & \multicolumn{2}{c}{ Collinearity Statistics } \\
\cline { 2 - 4 } 1 & & Tolerance & VIF \\
\cline { 2 - 4 } & CAR &, 921 & 1,085 \\
\cline { 2 - 4 } & LDR &, 919 & 1,088 \\
\cline { 2 - 4 } & NPL &, 889 & 1,125 \\
\cline { 2 - 4 } & BOPO &, 956 & 1,047 \\
\hline a. Dependent Variable: ROA & &
\end{tabular}

Berdasarkan Tabel 3 dapat dilihat nilai VIF CAR adalah 1,085 dan LDR adalah 1,088, dan nilai VIF NPL adalah 1,125, dan nilai VIF BOPO adalah 1,047. Jadi tidak terjadi multikolinieritas karena nilai VIF lebih kecil dari 10, sehingga tahapan pengolahan dapat dilanjutkan.

\section{Uji Heterokedastitas}

Tidak terjadi heterokedastitas apabila hasilnya sig $>0,05$. Tabel 4 merupakan nilai heterokedastitas. 


\section{Tabel 4}

\section{Hasil Uji Heterokedastitas}

\begin{tabular}{|c|c|c|c|c|c|c|}
\hline \multicolumn{7}{|c|}{ Coefficients ${ }^{a}$} \\
\hline \multirow{2}{*}{\multicolumn{2}{|c|}{ Model }} & \multicolumn{2}{|c|}{ Unstandardized Coefficients } & \multirow{2}{*}{$\begin{array}{c}\text { Standardized } \\
\text { Coefficients } \\
\text { Beta }\end{array}$} & \multirow[b]{2}{*}{$\mathrm{t}$} & \multirow[b]{2}{*}{ Sig. } \\
\hline & & $\mathrm{B}$ & Std. Error & & & \\
\hline \multirow[t]{5}{*}{1} & (Constant) & ,391 & 203 & & 1,931 &, 057 \\
\hline & CAR & ,001 &, 002 & 038 & ,342 & ,733 \\
\hline & LDR &, 002 &, 001 &, 181 & 1,636 & , 106 \\
\hline & NPL & ,011 &, 013 &, 095 & ,839 & ,404 \\
\hline & BOPO &,- 004 &, 002 &,- 262 & $-2,404$ & .059 \\
\hline
\end{tabular}

Berdasarkan Tabel 4 nilai sig 0,733 untuk variabel CAR, 50,106 untuk variabel LDR, 0, 404 untuk variabel NPL, dan 0,059 untuk variabel BOPO. Disimpulkan tidak terjadi gejala heterokedastitas.

\section{Uji Autokorelasi}

Autokorelasi jika nilai Durbin-Watson sebesar 1,822. Nilai tabel DW nipada signifikansi 5\%, jumlah sampel 84, dan variabel independen $4(\mathrm{k}=4)$, didapatkan nilai du sebesar 1,747 dan nilai dl sebesar 1,550. Nilai Durbin-Watson dilihat pada Tabel berikut ini:

\section{Tabel 5}

\section{Hasil Uji Autokorelasi}

Model Summary

\begin{tabular}{l|l} 
Adjusted R & Std. Error of the
\end{tabular}

\begin{tabular}{|c|c|c|c|c|c|}
\hline Model & $\mathrm{R}$ & R Square & $\begin{array}{c}\text { Adjusted R } \\
\text { Square }\end{array}$ & $\begin{array}{l}\text { Std. Error of the } \\
\text { Estimate }\end{array}$ & Durbin-Watson \\
\hline 1 & $962^{\mathrm{a}}$ & ,925 & 921 & 29800 & 1,822 \\
\hline
\end{tabular}

a. Predictors: (Constant), BOPO, CAR, LDR, NPL

b. Dependent Variable: ROA

Berdasarkan Tabel 5, maka tidak ada gejala autokorelasi positif atau negatif karena, 1,747 < $1,822<2,253$,

\section{Pengujian Hipotesis}

\section{Persamaan Regresi Linier Berganda}

Untuk melihat model persamaan regresi dapat disajikan pada tabel berikut ini.

Tabel 6

\section{Regresi Linier Berganda}

Coefficients ${ }^{\mathrm{a}}$

\begin{tabular}{|c|c|c|c|c|}
\hline \multirow{2}{*}{\multicolumn{2}{|c|}{ Model }} & \multicolumn{2}{|c|}{ Unstandardized Coefficients } & \multirow{2}{*}{$\begin{array}{c}\text { Standardized Coefficients } \\
\text { Beta } \\
\end{array}$} \\
\hline & & $\mathrm{B}$ & Std. Error & \\
\hline \multirow[t]{5}{*}{1} & (Constant) & 9,714 &, 350 & \\
\hline & CAR &,- 001 &, 004 &,- 007 \\
\hline & LDR & 001 &, 002 &,- 006 \\
\hline & NPL &,- 101 & ,023 &,- 145 \\
\hline & BOPO &,- 094 & ,003 &,- 929 \\
\hline
\end{tabular}


Berdasarkan tabel 6 model persamaan regresi linier berganda adalah sebagai berikut.

$$
\mathrm{Y}=9,714-0,001 \mathrm{CAR}+0,001 \mathrm{LDR}-0,101 \mathrm{NPL}-0,094 \mathrm{BOPO}+\mu \mathrm{i}
$$

Persamaan regresi linier berganda di atas memberikan gambaran bahwa:

1) Konstanta mempuyai nilai 9,714 yang artinya tanpa ada CAR, LDR, NPL, dan BOPO maka ROA telah mencapai 9,714. Ini berarti bahwa ROA akan kecil tanpa CAR, LDR, NPL, dan BOPO

2) Variabel CAR mempunyai nilai koefisien regresi sebesar -0,001. Jika setiap satuan penurunan CAR, akan dapat menurunkan ROA (Y) sebesar -0,001 dalam setiap satuannya. Apabila tidak ada perubahan dari variabel lain. Variabel $L D R$ mempunyai nilai koefisien regresi $=0,001$. Jika peningkatan setiap satuan $L D R$ akan meningkatkan ROA (Y) sebesar 0,001 dalam setiap satuannya. Apabila variabel lain tidak mengalami perubahan

3) Variabel NPL mempunyai nilai koefisien regresi sebesar -0,101. Jika setiap satuan NPL mengalami penurunan, akan maka ROA (Y) sebesar -0,101 dalam setiap satuannya akan mengalami penurunan juga. Apabila variabel lain tidak mengalami perubahan.

4) Variabel BOPO mempunyai nilai koefisien regresi sebesar -0,094. Hal ini berarti dengan adanya penurunan BOPO dalam setiap satuannya, akan dapat menurunkan ROA (Y) sebesar -0,094 dalam setiap satuannya. Apabila variabel lain tidak mengalami perubahan.

\section{Koefisien Determinasi}

Koefisien determinasi adalah seberapa besar persentase variabel independen menjelaskan variabel dependen. Hasil uji koefisien determinasi disajikan pada tabel 7 berikut ini.

Tabel 7

Koefisien Determinasi

\begin{tabular}{lr|r|rr|r}
\hline Model & $\mathrm{R}$ & \multicolumn{2}{c}{ R Square } & Adjusted R Square & \multicolumn{2}{c}{ Std. Error of the Estimate } \\
\hline 1 &, $912^{\mathrm{a}}$ &, 831 &, 747 &, 25200 \\
\hline
\end{tabular}

a. Predictors: (Constant), BOPO, CAR, LDR, NPL

b. Dependent Variable: ROA

Dari tabel 7 diperoleh koefisien determinasi (adjusted $\mathrm{R}^{2}$ ) $=0,747$. Hal ini menunjukkan bahwa sebesar $74,7 \%$ nilai ROA dipengaruhi oleh variabel CAR, LDR, NPL, dan BOPO, sedangkan sisanya $(100 \%-74,7 \%=25,3 \%)$ dipengaruhi oleh faktor-faktor lain yang tidak diteliti.

\section{Hasil Uji Hipotesis}

\section{Tabel 8}

Hasil Pegujian Hipotesis untuk Uji t

Coefficients $^{\mathbf{a}}$

\begin{tabular}{|c|c|c|c|c|c|c|}
\hline \multirow[b]{2}{*}{ Mode } & & \multicolumn{2}{|c|}{ Unstandardized Coefficients } & \multirow{2}{*}{$\begin{array}{c}\begin{array}{c}\text { Standardized } \\
\text { Coefficients }\end{array} \\
\text { Beta } \\
\end{array}$} & \multirow[b]{2}{*}{$\mathrm{t}$} & \multirow[b]{2}{*}{ Sig. } \\
\hline & & $\mathrm{B}$ & Std. Error & & & \\
\hline \multirow[t]{5}{*}{1} & (Constant) & 9,714 & ,350 & & 27,742 &, 000 \\
\hline & CAR &,- 001 & 004 &,- 007 &,- 207 & 837 \\
\hline & LDR & 001 &, 002 &,- 006 &,- 199 & ,843 \\
\hline & NPL &,- 101 & ,023 &,- 145 & $-4,444$ & ,000 \\
\hline & BOPO &,- 094 & ,003 &,- 929 & $-29,478$ &, 000 \\
\hline
\end{tabular}

a. Dependent Variable: ROA 
Berdasarkan tabel 8 dengan menggunakan t-test, diperoleh nilai t hitung yaitu Uji $t$ terhadap Variabel CAR diperoleh nilai t-statistik sebesar -0,207 lebih kecil dari nilai t tabel $1,98(\alpha=5 \%)$, nilai sig $\leq \alpha 0,05$ yaitu 0,837 , maka keputusannya adalah Ho diterima dan Ha ditolak. Jadi variabel CAR dalam penelitian ini memberikan pengaruh negatif terhadap ROA. Uji t terhadap Variabel $L D R$ diperoleh nilai t-statistik sebesar -0,199 lebih kecil dari nilai $\mathrm{t}$ tabel 1,98 $(\alpha=5 \%)$, nilai sig $\leq \alpha 0,05$ yaitu 0,843 , maka keputusannya adalah Ho diterima dan Ha ditolak. Jadi variabel $L D R$ berpengaruh tidak signifikan terhadap ROA.

\section{Pembahasan}

\section{Pengaruh CAR terhadap ROA}

Hasil penelitian mengungkapkan bahwa variabel CAR dalam penelitian ini memberikan penaruh negatif tidak signifikan terhadap ROA. Semakin besar jumlah modal yang disediakan bank (CAR) tidak berpengaruh terhadap profitabilitas bank umum di Indonesia. Kemungkinan CAR memiliki pengaruh negatif terhadap ROA karena adanya bobot risiko yang berasal dari kredit. Adanya kenaikan kredit maka akan ada kenaikan total aset tertimbang menurut risiko yang berarti juga akan menurunkan CAR. Penurunan CAR yang disebabkan oleh kenaikan kredit menyebabkan semakin banyaknya pendapatan bunga bank. Hal tersebut meningkatkan laba sebelum pajak sehingga ROA akan meningkat. CAR adalah indikator kecukupan modal yang digunakan untuk menilai kesehatan bank. Kecukupan modal terkait dengan penyediaan modal sendiri yang diperlukan untuk menutupi risiko kerugian yang timbul dari pergerakan aset bank, yang pada dasarnya mayoritas sumber dana dana pihak ketiga atau publik. Jika CAR perusahaan meningkat, maka kemampuan bank untuk menanggung risiko pembiayaan juga meningkat.

Hasil penelitian ini sejalan dengan hasil penelitian yang dilakukan oleh Wibowo, Syaichu, \& Manajemen (2013); Erlangga \& Mawardi (2016); Munir (2018); Oktaviani, Suyono, \& Mujiono (2019) \& Madugu, Ibrahim, \& Amoah (2020) mengungkapkan bahwa bahwa CAR tidak berpengaruh terhadap ROA.

\section{Pengaruh LDR terhadap ROA}

Hasil penelitian mengungkapkan bahwa variabel $L D R$ dalam penelitian ini memberikan pengaruh tidak signifikan terhadap ROA. Semakin rendah rasio LDR menunjukkan semakin rendah dana yang disalurkan dan semakin rendah LDR menunjukkan kurangnya efektifitas bank dalam menyalurkan kredit dan pada akhirnya keuntungan juga semakin rendah (ROA). LDR yang lebih tinggi pada lembaga keuangan tidak likuid atau perusahaan tidak dapat memenuhi kewajibannya, sedangkan ketika tingkat rasio yang rendah menunjukkan bahwa bank itu likuid atau perusahaan dapat memenuhi kewajibannya. Bank yang berada dalam kondisi tidak likuid akan mengalami kesulitan untuk mendapatkan kembali kepercayaan publik dan melakukan kegiatan operasional utama bank dalam menyalurkan kapal keruk sehingga berdampak pada profitabilitas tinggi dan rendah.

Hasil penelitian ini sejalan dengan study yang dilakukan oleh Avrita \& Pangestuti (2016); Oktaviani et al. (2019);Dewi, Mulyadi, \& Adurrakhman (2015); Majidi (2016) \& Atmoko, Amboningtyas, \& Fathoni (2018) yang menyatakan bahwa Loan to Deposit Ratio tidak berpengaruh terhadap profitabilitas (ROA).

\section{Pengaruh NPL terhadap ROA}

Hasil penelitian mengungkapkan bahwa variabel NPL dalam penelitian ini memberikan pengaruh secara signifikan terhadap ROA. Hal ini dikarenakan pinjaman macet mengikis profitabilitas bank sehingga bank bisa mengeluarkan biaya pembuangan yang besar. Pinjaman bermasalah memiliki biaya peluang, di mana aset produktif tanpa bunga (terutama dalam bentuk uang) dapat diinvestasikan di tempat lain dan memberikan penghasilan. Selain 
itu, Bank juga diharuskan untuk membuat cadangan kerugian atas aset bermasalah yang pada gilirannya mempengaruhi profitabilitas dan ada biaya yang terkait dengan upaya untuk memulihkan kredit macet. Kinerja keuangan adalah diukur dalam hal pengembalian aset (ROA) sementara kredit bermasalah (NPL) diukur sebagai rasio NPL (yang dihitung sebagai persentase kredit bermasalah terhadap pinjaman bruto, dengan demikian NPL Bruto / Pinjaman bruto).

Hasil penelitian ini sejalan dengan hasil study yang dilakukan oleh Mardi \& Faradila (2016); Yusriani (2018); Vernanda \& Widyarti (2016); Amin Moh (2019) \& Alshebmi, Mohammad Adam, Mustafa, Thomran, \& Fathelbab (2020) yang menyatakan bahwa Hasil korelasi menunjukkan hubungan lemah, negatif secara signifikan antara rasio kredit bermasalah (NPL) dan rasio pengembalian aset (ROA).

\section{Pengaruh BOPO terhadap ROA}

Hasil penelitian menunjukkan BOPO memiliki dampak negatif pada ROA. Sehingga semakin kecil BOPO maka semakin meningkat pula (ROA) bank. Sebaliknya. Hal ini dikarenakan adanya angsuran biaya kerja, sehingga keuntungan yang dihasilkan oleh bank akan berkurang. Jika biaya operasional semakin besar, maka pendapatan operasional bank akan berkurang. Hal ini memengaruhi berkurangnya total laba sebelum pajak bank dan pada akhirnya terjadilah penurunan ROA.

BOPO merupakan rasioyang mengukur proporsi antara biaya kerja dan upah kerja. Rasio ini digunakan untuk mengukur tingkat efektivitas dan kapasitas bank dalam menyelesaikan kegiatan operasional. Semakin kecil nilai rasio ini, semakin efisien bank mengeluarkan biaya operasional, dengan efisiensi biaya membuat laba diambil oleh bank, dengan cara profitabilitas. Hasil penelitian ini didukung oleh hasil riset yang dilakukan oleh Ahmed Mennawi \& Ahmed(2020); Wibowo et al. (2013); Amin Moh (2019); Putra (2020) \& Hosen, Jie, Muhari, \& Khairman (2019) yang menyatakan bahwa BOPO memiliki dampak negatif dan signifikan terhadap profitabilitas bank.

\section{KESIMPULAN}

Berdasarkan hasil pemeriksaan statistik deskriptif, maka didapat hasil sebagai berikut: (1) Capital Adequacy Ratio (CAR) tidak berpengaruh terhadap ROA bank umum di Indonesia periode 2017-2019. (2) LDR berpengaruh positif dan signifikan terhadap ROA bank umum di Indonesia periode 2017-2019. (3) NPL berdampak negatif terhadap ROA bank umum di Indonesia periode 2017-2019. (4) BOPO berdampak negatif terhadap ROA Bank Umum di Indonesia periode 2017-2019.

\section{SARAN}

Manfaat penelitian yang telah dilakukan, maka usulan yang diberikan sebagai berikut: (1) Untuk peneliti dapat menambah dan menguji berbagai faktor yang dapat mempengaruhi profitabilitas dalam organisasi keuangan, misalnya, Net Profit Margin (NPM) dan Net Interest Margin (NIM). (2) Bagi Regulator (Bank Indonesia), dalam meningkatkan produktivitas atau Return on Assets (ROA) yang diperoleh bank, penting untuk menyaring Kredit Macet (NPL) yang wajar dan adil agar tidak menimbulkan kredit macet yang mempengaruhi penurunan manfaat bagi organisasi dan menjaga Biaya Operasional Terhadap Pendapatan Operasi (BOPO) di bawah 90\% yang ditetapkan oleh Bank Indonesia. (3) Investor perlu mempelajari perusahaan mana yang memiliki Non Performing Loan (NPL) dalam rentang - 92\% dan Non Performing Loan (NPL) yang berada di bawah titik tertinggi yang ditetapkan oleh Bank Indonesia sebesar 5\% dan Biaya Operasional di bawah 90\%. (4) Bagi Bank, untuk meningkatkan produktivitas atau Return on Assets (ROA) yang akan diakuisisi, perusahaan harus menekan Biaya Operasional Terhadap Pendapatan Operasional 
(BOPO) secara progresif sejauh mungkin dan dengan mengurangi tingkat kredit yang buruk atau Non Performing Loans (NPL). ) sehingga jauh dari batasan paling ekstrem 5\%.

\section{DAFTAR PUSTAKA}

Ahmed Mennawi, A. N., \& Ahmed, A. A. (2020). Influential Factors on Profitability of Islamic Banks: Evidence from Sudan. International Journal of Economics and Finance.

Alshebmi, A. S., Mohammad Adam, M. H., Mustafa, A. M. A., Thomran, M., \& Fathelbab, O. E. A. (2020). Assessing The Non-Performing Loans And Their Effect On Banks Profitability: An Empirical Evidence From The Saudi Arabia Banking Sector. International Journal of Innovation, Creativity and Change.

Amin Moh, M. W. A. (2019). Pengaruh Dpk, Npl Dan Bopo Terhadap Profitabilitas Perbankan Yang Terdaftar Di Bursa Efek Indonesia. Jurnal Ilmiah Riset Akuntansi.

Atmoko, A. S., Amboningtyas, D., \& Fathoni, A. (2018). Effectof LDR, NPL and BOPO on Profitabilitas Based on CAR. Journal of Management.

Avrita, R. D., \& Pangestuti, I. R. D. (2016). Analisis Pengaruh CAR, NPL, LDR, NIM, dan BOPO Terhadap Profitabilitas Bank (Perbandingan Bank UmumGo Public Dan Bank Umum Non Go Public Di Indonesia Periode Tahun 2011-2014). Diponegoro Journal Of Management.

Birkenmaier, J. (2012). Promoting Bank Accounts to Low-Income Households: Implications for Social Work Practice. Journal of Community Practice.

Chandrasegaran, L. (2020). Capital Adequacy Requirements and Profitability: An Empirical Study on Banking Industry in Sri Lanka. Journal of Economics and Business, 3(2).

Dewi, P. K., Mulyadi, \& Adurrakhman. (2015). Analisis Pengaruh CAR, NPL, LDR, dan NIM terhadap Profitabilitas Perbankan (Studi Kasus Pada Bank Umum yang Tercatat Pada BEI Tahun 2008-2012). Journal of Auditing, Finance, and Forrensic Accounting.

Epure, M., \& Lafuente, E. (2015). Monitoring bank performance in the presence of risk. Journal of Productivity Analysis.

Erlangga, O. P., \& Mawardi, I. (2016). Pengaruh Total Aktiva, Capital Adequacy Ratio (CAR), Finance To Deposit Ratio (FDR) Dan Non Performing Financing (NPF) Terhadap Return on Assets (ROA) Bank Umum Syariah Di Indonesia Periode 20102014. Jurnal Ekonomi Syariah Teori Dan Terapan.

Hosen, M. N., Jie, F., Muhari, S., \& Khairman, M. (2019). The Effect of Financial Ratios, Maqasid Sharia Index, and Index of Islamic Social Reporting to Profitability of Islamic Bank in Indonesia. Al-Iqtishad: Jurnal Ilmu Ekonomi Syariah.

Joyce Jepkosgei Kipruto, Matanda, W. J., \& Osodo, O. P. (2017). the Influence of Capital Adequacy Ratio on the Financial Performance of Second-Tier Commercial Banks in Kenya. International Journal of Business and Management Review, 5(10), 13-23.

Kasmir. (2012). Manajemen Perbankan. Jakarta: Rajawali Pers.

Madugu, A. H., Ibrahim, M., \& Amoah, J. O. (2020). Differential effects of credit risk and capital adequacy ratio on profitability of the domestic banking sector in Ghana. Transnational Corporations Review.

Majidi, Z. (2016). Analisis Pengaruh CAR, NPL, Dan LDR terhadap Profitabilitas pada Perusahaan Perbankan yang Listing di BEI (2014-2016). Accounting Analysis Journal.

Mardi, M., \& Faradila, L. (2016). Pengaruh Non Performing Loan (NPL) Dan Bunga Pinjaman Terhadap Tingkat Profitabilitas Bank Umum Swasta Nasional. Jurnal Organisasi dan Manajemen.

Matindas, A. M., Pangemanan, S. S., \& Saerang, D. P. E. (2015). Pengaruh Capital Adequacy Ratio (Car), Bopo Dan Non Performing Loan (Npl) Terhadap Kinerja Keuangan Perbankan Di Indonesia. Going Concern : Jurnal Riset AkuntansI. 
Munir, M. (2018). Analisis Pengaruh CAR, NPF, FDR dan Inflasi terhadap Profitabilitas Perbankan Syariah di Indonesia. Ihtifaz: Journal of Islamic Economics, Finance, and Banking.

Oktaviani, S., Suyono, \& Mujiono. (2019). Analysis The Effect Of CAR, BOPO, LDR, NIM And Firm Size On Profitability Of Banks Listed On IDX Period 2012-2017. Bilancia Jurnal Ilmiah Akuntansi.

Osborne, M., Fuertes, A. M., \& Milne, A. (2017). In good times and in bad: Bank capital ratios and lending rates. International Review of Financial Analysis.

Putra, H. M. (2020). Pengaruh CAR, NPF,BOPO DAN LDR Terhadap ROA Bank Umum Syariah Yang Terdaftar Di Bank Indonesia. Jurnal Ilmu Manajemen (JIMMU).

Tan, Y., \& Anchor, J. (2016). Stability and profitability in the Chinese banking Industry: Evidence from an auto-regressive-distributed linear specification. Investment Management and Financial Innovations.

Van den End, J. W. (2016). A Macroprudential Approach To Address Liquidity Risk With The Loan-To-Deposit Ratio. European Journal of Finance.

Vernanda, S. D., \& Widyarti, E. T. (2016). Analisis Pengaruh CAR, LDR, NPL, BOPO, dan SIZE Terhadap ROA (Studi pada Bank Umum Konvensional yang Terdaftar di Bursa Efek Indonesia Periode 2010-2015). Diponegoro Journal of Management.

Wibowo, E. S., Syaichu, M., \& Manajemen, J. (2013). Analisis Pengaruh Suku Bunga, Inflasi, CAR, BOPO, NPF Terhadap Profitabilitas Bank Syariah. Diponegoro Journal Of Management.

Yusriani. (2018). Pengaruh CAR, NPL, BOPO dan LDR Terhadap Profitabilitas Pada Bank Umum Milik Negara Persero di Bursa Efek Indonesia. Jurnal Riset Edisi XXV. 